\author{
G.I. Barylo, R.L. Holyaka, T.A. Marusenkova, M.S. Ivakh
}

\title{
Structure and 3-D Model of a Solid State Thin-Film Magnetic Sensor
}

\author{
Lviv Polytechnic National University, Lviv, Ukraine, roman.l.holiaka@lpnu.ua
}

\begin{abstract}
Vector 3-D magnetic sensors form the basis of measurement devices for magnetic field mapping and magnetic tracking. Typically, such sensors utilize specific constructions based on split Hall structures (SHS). An SHS-based 3-D magnetic sensor is a bulk semiconductor integrated structure with 8 or more contacts. Combining current flow directions through the contacts and measuring the corresponding voltages, one defines projections $\mathrm{B}_{\mathrm{X}}, \mathrm{B}_{\mathrm{Y}}, \mathrm{B}_{\mathrm{Z}}$ of the magnetic field vector. This work presents a novel design of 3-D solid state magnetic sensors that requires no insulation by $\mathrm{p}$-n junctions and can be implemented by thin-film technology traditionally used for fabrication of Hall sensors including those based on InSb films. Besides, a SPICE model of the 3-D magnetic sensor is provided, which helps design the proposed sensor and refine techniques of its calibration.

Keywords: 3-D magnetic sensor, split Hall structures, SPICE model.
\end{abstract}

Received 7 May 2021; Accepted 27 July 2021.

\section{Introduction}

Nowadays 3-Dimensions (3-D) magnetic sensors able to measure three mutually orthogonal components $\mathrm{B}_{\mathrm{X}}, \mathrm{B}_{\mathrm{Y}}$ and $\mathrm{B}_{\mathrm{Z}}$ of the magnetic flux density are of high interest. Such 3-D sensors use a specific combination of horizontal (normal) Hall sensors with vertical (tangential) Hall sensors, split Hall structures (SHS), or magnetotransistors. Typically, vector 3-D magnetic sensors form the basis of measurement devices for magnetic field mapping and defining the spatial position of objects in a reference magnetic field in different application areas including magnetic tracking [1].

An SHS-based 3-D magnetic sensor is designed as a bulk semiconductor integrated structure with 8 or more electrodes. Combining current flows through these electrodes and measuring the corresponding voltages, one defines projections $\mathrm{B}_{\mathrm{X}}, \mathrm{B}_{\mathrm{Y}}, \mathrm{B}_{\mathrm{Z}}$ of the magnetic flux density vector. Typically, such an integrated 3-D sensor incorporates one component that serves as a traditional SHS whose sensitive axis (Z) is perpendicular to the semiconductor layer plane and two other components whose sensitive axes ( $\mathrm{X}$ and $\mathrm{Y}$ ) are parallel to the semiconductor layer plane. The latter two components are called vertical SHSs. Magnetotransistors are a bulk semiconductor integrated structure built upon dualcollector lateral transistors whose geometry is optimized in order to achieve high sensitivity of collector currents to the magnetic field.

It should be emphasized that fabrication of both SHS-based and magnetotransistor-based 3-D sensors requires structures that can only be obtained by solidstate silicon integrated circuit technology. However, such structures and, first of all, their p-n junctions, can boast neither high radiation nor thermal stability, which narrows the application area of most available 3-D sensors.

The creation of vector 3-D magnetic sensors of a new generation is in high demand, primarily for usage in space, particle accelerators, and thermonuclear fusion reactors. This work presents a new design of 3-D magnetic sensors that can dispense with $p-n$ junctions and be implemented by thin-film technology traditionally used for manufacturing Hall sensors, including those based on InSb films. Due to this one can create 3-D sensors resistant to harsh environments, for instance, for magnetic field diagnostics in thermonuclear fusion reactors or increased radiation in industrial disaster 
management devices. Besides, the work proposes a SPICE model of a 3-D magnetic sensor which can be used when designing the proposed sensor and refining its calibration technique.

\section{Literature overview}

Let us consider typical problems of 3-D magnetic sensor design, research, and usage by examples of the newest scientific literature sources. Magnetic field vector sensor using magnetoelectric thin-film composites was proposed in [2], monolithic integrated 3-D magnetic field sensor based on MEMS technology - in [3], single-chip integrated 3-D Hall sensor - in [4], three-dimensional field sensing with magnetotransistors - in [5], low power 3D-magnetotransistor based on CMOS (Complementary Metal-Oxide-Semiconductor) technology - in [6].

In [7] measurement characteristics of different integrated 3D magnetic field sensors were studied, whereas [8] discussed planarization, fabrication, and characterization. Crosstalk analysis and current measurement correction in circular 3D magnetic sensors arrays were given in [9]. In [10] misalignment and magnetic cross-sensitivity of integrated vertical Hall sensors were considered.

The literature covers problems of integrating 3-D magnetic sensors with other sensor technologies, including functionally integrated sensors on magnetic and thermal methods [11] and soft magnetic 3-D Force sensor [12]. In [13] a 3D magnetic field sensor concept for use in inertial measurement units was presented. Implementation of 3D magnetic field sensors for magnetic tracking was presented in [14, 15] and for labs instrumentation - in [16]. Silicon on Insulator (SOI) 3-D structures for System-on-Chip Applications presented in [17], as well as, device-technological simulation of local 3-D SOI structures - in [18].

Problems of 3D sensor simulation are discussed in the following publications: 3-D finite-element analysis of Giant magnetoimpedance thin-film magnetic sensors [19], a numerical methodology for a 6 DOF (Degrees Of Freedom) pose estimation with 3D magnetic field sensors [20], spatial models of split Hall structures [21]. Key issues of $3 \mathrm{D}$ sensor simulation are detection of dependencies for further enhancement of sensor calibration techniques, including arbitrary rotation method for 3D magnetic sensors calibration [22].

For the thin-film magnetic sensor presented in this article, SPICE (Simulation Program with Integrated Circuit Emphasis) modeling is used. SPICE includes many semiconductor device models, for example, resistors, capacitors, inductors, diodes, transistors. Up-todate versions of SPICE comprise independent voltage and current sources, ideal transmission lines, active components, and voltage and current controlled sources three levels of MOSFET (Metal-Oxide-Semiconductor Field Effect Transistor) model, a combined Ebers-Moll and Gummel-Poon bipolar model, etc.

Modern SPICE simulation concerns a wide range of scientific problems. To name a few, it includes developing models of memristor [23], ferroelectric transistors [24], thermoelectric module [25]. SPICE simulation of magnetic field sensors is covered in the following publications: Physical simulations of response time in Hall sensor devices [26], Behavioral model of magnetic sensors for SPICE simulations [27], Analysis and Modeling of One-Dimensional Folded Vertical Hall Sensor with Readout Circuit [28].

Upon the analysis of the above-mentioned literature sources, one can state that problems of 3-D magnetic sensor simulation and usage are of current interest.

\section{Structure and operation principle}

The novelty of the approach presented in this work is the possibility of manufacturing 3-D magnetic sensors by thin-film technology. A 3-D thin-film sensor incorporates two equally-shaped vertical SHSs placed orthogonally. Fig. 1 depicts a simplified design of one such SHS, the one intended for measuring projection $\mathrm{B}_{\mathrm{X}}$ of the magnetic flux density vector. In Fig. 1 the following notations are used: 1 - substrate, 2 - semiconductor active area, 3 - central current electrode, 4 and 5 - lateral current electrodes, 6 and 7 - potential electrodes, 8 and 9 - auxiliary areas, 10 and 11 - intermediate areas. Intersection A-A of the vertical SHS and the directions of the magnetic flux density vector projections have been shown in Fig. 1 as well. Projections $B_{X}$ and $B_{Y}$ lie in the
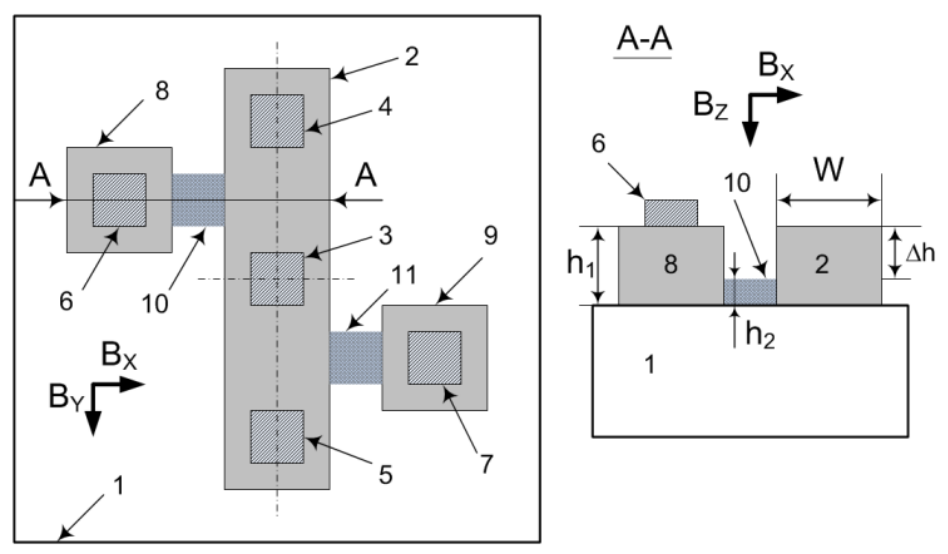

Fig. 1. Design of a vertical thin-film SHS. 
plane of the transducer whereas projection $B_{Z}$ is perpendicular to this plane.

A simplified description of the SHS manufacturing process is as follows. A semiconductor InSb epitaxial film of thickness $\mathrm{h}_{1}=10^{-5} \mathrm{~m}$ and doping concentration $\mathrm{N}$ $=10^{16} \div 10^{17} \mathrm{~cm}^{-3}$ is grown on a high-resistance GaAs substrate. A contact system that provides a lowresistance ohmic contact to $\mathrm{InSb}$ and serves as contact areas is formed on the InSb epitaxial film by metallization with metals such as $\mathrm{Au}, \mathrm{Cu}$, etc. The structure is manufactured in three stages. The first stage is aimed at etching the contact system. The second one is intended for etching an InSb film spanning across the whole thickness, $\mathrm{h}_{1}$. During the third stage an InSb film spanning across nearly $90 \%$ of the film thickness, $\mathrm{h}_{2}$, should be etched. Such incomplete etching of a semiconductor film in specific areas of the structure along with the corresponding structure geometry enables the implementation of a 3-D thin-film magnetic sensor. It is of key importance that thickness $\mathrm{h}_{2}$ of the intermediate areas, which are denoted 10 and 11 in Fig. 1, is much less than the thickness of the active area denoted 2 .

A new solution is the principle of forming signals and the design of the basic component of such 3-D sensors - the vertical SHS. In contrast to known solutions, the potential (Hall) electrodes of the vertical SHS are formed inside the semiconductor layer rather than on its surface. Namely, the potential electrodes reside in the intermediate area $\Delta \mathrm{h}$ between the semiconductor layer and either dielectric or highresistance semiconductor substrate. It enables the manufacturing of such sensors with no p-n junctions and no dielectric layer between the semiconductor and metallization layers.

The operation principle of a vertical thin-film SHS is as follows. The transducer is connected to a power supply, usually a direct-current source. With this purpose central current electrode 3 is connected to the first electrode of the power supply whereas lateral current electrodes 4 and 5 are connected together to the second electrode of the power supply. Thus, current in the working area is distributed equally and flows in two opposite directions with respect to the central current electrode.

Neglecting current in the circuits of two potential electrodes 6 and 7 one can assume that the potentials on these electrodes are equal to the corresponding potentials of intermediate areas 10 and 11. In this way, the design of the transducer enables forming an output voltage on potential electrodes 6 and 7 that is equal to the voltage difference between the areas in the bottom surface of the active area near their contact with intermediate areas 10 and 11. As has been mentioned before, intermediate areas 10 and 11 are much thinner than active area 2, which ensures that the very potentials of the bottom surface of the active area are formed on potential electrodes 6 and 7 .

In general case, the voltages on potential electrodes 6 and 7 consist of three components. The first component, $\mathrm{V}_{\mathrm{R}}$, is caused by voltage drop at semiconductor active area 2. Taking into account that the active area is symmetric with respect to the first current electrode 3 , the first components of the voltage on potential electrodes 6 and 7 are equal: $V_{R}(6)=V_{R}(7)$. The second component, $\mathrm{V}_{\mathrm{Z}}$, is caused by projection $\mathrm{B}_{\mathrm{Z}}$ of the magnetic flux density vector that is perpendicular to the transducer plane. Taking into account the transducer design and current flow directions in it, the second components of the voltage on potential electrodes 6 and 7 are equal as well, i.e., $\mathrm{V}_{\mathrm{Z}}(6)=\mathrm{V}_{\mathrm{Z}}(7)$. The third component, $\mathrm{V}_{\mathrm{X}}$, is influenced by projection $\mathrm{B}_{\mathrm{X}}$ of the magnetic flux density vector. In contrast to the previously mentioned two voltage components, this one has the opposite signs on potential electrodes 6 and 7: $\mathrm{V}_{\mathrm{X}}(6)=-\mathrm{V}_{\mathrm{X}}(7)$. Particularly, under the influence of the Lorentz force in the top part (Fig. 2) of active area 2 charge carriers deflect to the top surface of the semiconductor layer whereas in the bottom part they deflect to the bottom surface, towards the substrate. The difference in potentials that occurs due to such deflection of charge carriers is transmitted to potential electrodes 6 and 7 through intermediate areas 10 and 11. It is worth mentioning that projection $\mathrm{B}_{\mathrm{Y}}$ of the magnetic flux density vector, which is parallel to the current flow direction in the active area, does not cause any charge carriers deflection and thus can be neglected: $\mathrm{V}_{\mathrm{Y}}(6)=\mathrm{V}_{\mathrm{Y}}(7)=0$.

Thus, the voltage difference between potential electrodes 6 and 7 depends only on projection $\mathrm{B}_{\mathrm{X}}$ of the magnetic flux density vector and can be considered nearly uninfluenced by the other two projections:
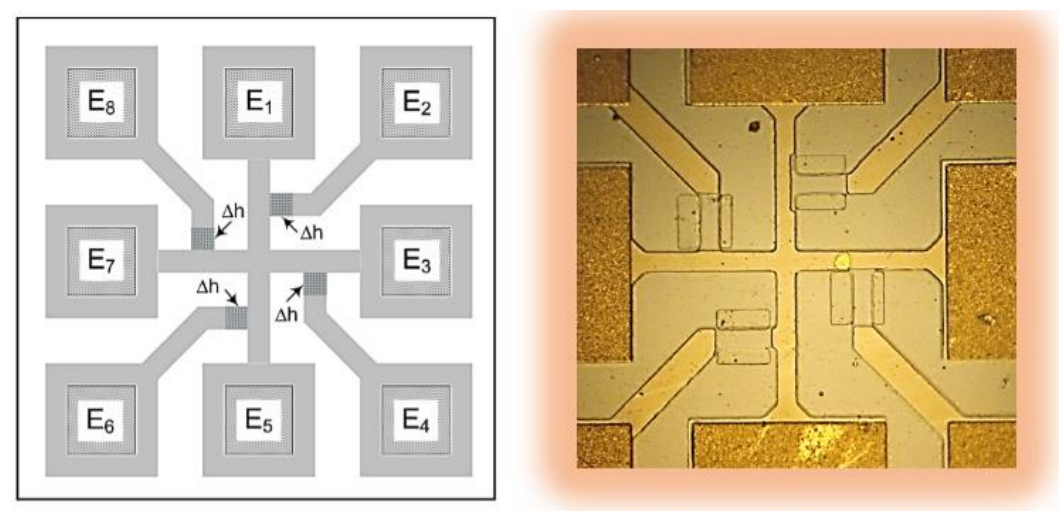

Fig. 2. Topology and a photo of a 3-D thin-film sensor. 


$$
V_{\text {OUT }}=\left[V_{R}(6)+V_{X}(6)+V_{Y}(6)+V_{Z}(6)\right]\left[V_{R}(7)+V_{X}(7)+V_{Y}(7)+V_{Z}(7)\right]=V_{X},
$$

where $\mathrm{V}_{\mathrm{X}}=\mathrm{V}_{\mathrm{X}}(6)+\mathrm{V}_{\mathrm{x}}(7)$.

As has been said before, the proposed 3-D thin-film sensor includes two orthogonally placed vertical SHSs that provide sensitivity to projections $\mathrm{B}_{\mathrm{X}}$ and $\mathrm{B}_{\mathrm{Y}}$ of the magnetic flux density vector, and a horizontal Hall sensor sensitive to projection $\mathrm{B}_{\mathrm{Z}}$.

Fig. 2 shows the topology and a photo of the active area of a 3-D thin-film sensor. The active area of the horizontal Hall sensor is the central part of the 3-D sensor, i.e., the area where two orthogonally placed vertical SHSs intersect. Obviously, such a solution does not allow us to place current electrode 3, which has been shown in Fig. 1, in the central part of the sensor.

This problem can be solved by an original approach to feeding the 3-D sensor. When measuring projections $B_{X}$ and $B_{Y}$ electrodes $E_{1}$ and $E_{5}$ of the 3-D sensor (Fig. 2) are connected to the positive electrode of the power supply whereas electrodes $\mathrm{E}_{3}$ and $\mathrm{E}_{7}$ are connected to its negative electrode. Thus, two current flows with opposite directions are ensured: the current flows down from electrode $E_{1}$ to the structure center and up from electrode $\mathrm{E}_{5}$ to the center. In the center of the structure these two current flows mix and then split again in two opposite directions - to the right, towards electrode $\mathrm{E}_{3}$, and to the left, towards electrode $\mathrm{E}_{7}$. These current flows with opposite directions in the proposed 3-D sensor are crucial for forming voltage differences $\mathrm{V}\left(\mathrm{E}_{6}\right)-\mathrm{V}\left(\mathrm{E}_{2}\right)$ and $\mathrm{V}\left(\mathrm{E}_{8}\right)$ $\mathrm{V}\left(\mathrm{E}_{4}\right)$ on the potential electrodes. The voltage differences are informative signals of projections $\mathrm{B}_{\mathrm{X}}$ and $\mathrm{B}_{\mathrm{Y}}$ of the magnetic flux density vector, correspondingly.

For measurement of projection $\mathrm{B}_{\mathrm{Z}}$, which is perpendicular to the sensor plane, only four electrodes are used. Electrodes $E_{1}$ and $E_{5}$ serve as current electrodes whereas $E_{3}$ and $E_{7}-$ as potential ones, which is a typical way of operating horizontal Hall sensors.

To ensure the same sensitivity for the three SHSs inside a 3-D sensor one should take into account the following fact. In contrast to traditional horizontal Hall sensors whose sensitivity is inversely proportional to the thickness of the semiconductor active area layer, sensitivity of vertical SHSs is inversely proportional to the width $\mathrm{W}$ of the semiconductor area (Fig. 1). That is why it is recommended that width $\mathrm{W}$ of the active area should be minimized and nearly equal to thickness $h_{1}$ of the semiconductor layer.

\section{SPICE model}

In contrast to traditional Hall sensors, SHSs have much more complex measurement conversion functions. Moreover, in order to obtain their signals one needs more complex signal transducers. That is why unified approaches to circuit simulation in SPICE allow us to simplify the synthesis and analysis of the equivalent circuit of an SHS. Having compared the signal families obtained during the analysis of these equivalent circuits with the experimental results, it is possible to refine the
SHS model and then form arrays of data that can be used for developing calibration techniques.

One should mention that for several reasons it is impossible to use SPICE or SPICE-based programs directly for magnetic sensors simulation. Firstly, SPICE libraries do not support any magnetic field parameters. Secondly, simulation analysis of Hall sensors, especially structurally complex ones that are based on SHS, should account for changes not only in the magnetic flux density but also in the sensor position in a magnetic field. Moreover, depending on the simulation analysis objectives the function can have the following arguments: the magnetic flux density vector length, the projections of the magnetic field vector onto the coordinate system associated with the sensor (its spatial position), the parameters of the sensor structure or temperature.

In order to solve the above-stated problem, we have developed basic approaches to the synthesis of SHS models based on equivalent circuits whose elements' parameters (voltage, current, resistance) are controlled by formal analogues. Such formal analogues are the parameters of auxiliary circuit components that formally describe the numerical values of the magnetic field, the position of the sensor in the magnetic field, and the coefficients of the functional characteristics of the sensor including its sensitivity, offset voltage, input, and output resistance, etc.

SPICE and MicroCAP libraries offer a wide range of typical components: resistors, capacitors, diodes, transistors, and controlled voltage and current sources (VofV, VofI, IofV, IofI, NFV, etc.) whose syntax allows to preset the dependencies of the source output on some specific voltages or currents in the circuit in analytical or table form. From the point of view of designing equivalent circuits for SHS, the models of the elements that synthesize such equivalent circuits should allow an analytical description of: controlled voltage sources for Hall voltages simulation; controlled resistors for modelling ohmic signal components; functional dependencies between the parameters of Hall sensors and the magnetic field vector components that are implemented by formal analogues and described using trigonometric functional relationships, particularly the dependencies of the Hall and ohmic signal components on the sensor tilt angle in the magnetic field.

Our analysis of the functional and parametric capabilities of the controlled sources has shown that controlled voltage sources of NFV type are the most reasonable choice for the synthesis of Hall voltages.

The functional dependency of the Hall voltage on angle $\alpha_{N}$ between the magnetic field vector $B$ and the perpendicular $\mathrm{N}$ to the sensor plane, $V_{H}=V_{M} \cos \alpha_{N}$, can be formally described analytically as $V(E)=V_{M} \cos (V(1) \cdot \pi / 180)$ where $\mathrm{V}(\mathrm{E})$ is the voltage of the NFV source $E ; V_{M}=1 V$ is the normalized maximum voltage; $\mathrm{V}(1)$ is the voltage in node (1) formed by 
voltage source $\mathrm{Va}$. The latter is the formal analogue of the tilt angle, $V(1)=V(V a) \equiv \alpha_{N}$, as shown in Fig. 3. An example of the modelling analogy obtained in this way is shown in Fig. 4.

For the synthesis of the magnetoresistive structure of the sensor, we will use a model of a functional resistor whose resistance can be set analytically. Fig. 5 depicts a sample result of synthesizing the quadratic dependency of resistance $R_{B}$ of the sensor resistive structure on magnetic flux density $\mathrm{B}: R_{B}(B)=R_{0}\left(1+K_{R B} B^{2}\right)$ in the form of dependency $R\left(R_{1}\right)=R_{0}\left(1+K_{R B} V(1)^{2}\right)$ where $\mathrm{R}_{0}=100$ is resistance at $\mathrm{B}=0 ; \mathrm{K}_{\mathrm{RB}}$ is the quadratic magnetoresistance coefficient; $\mathrm{V}(1)=\mathrm{V}(\mathrm{VB}) \equiv \mathrm{B}$ is the formal analogue of the magnetic flux density.

Upon the above-mentioned approaches for component specification, we have synthesized an equivalent circuit (Fig. 6) for the SPICE model of the thin-film vector sensor depicted in Fig. 2. The presented model uses the following functional components as formal analogues: VB as the analogue of the magnetic flux density vector B; Valf and Vbet as analogues of angles $\alpha$ and $\beta$ of the magnetic flux density vector orientation in respect to the SHS plane; RE and RV as analogues of the magnetoresistance coefficient; EBX, EBY, EBZ as analogues of the Hall voltages in the SHS in respect to axes $\mathrm{X}, \mathrm{Y}, \mathrm{Z}$.

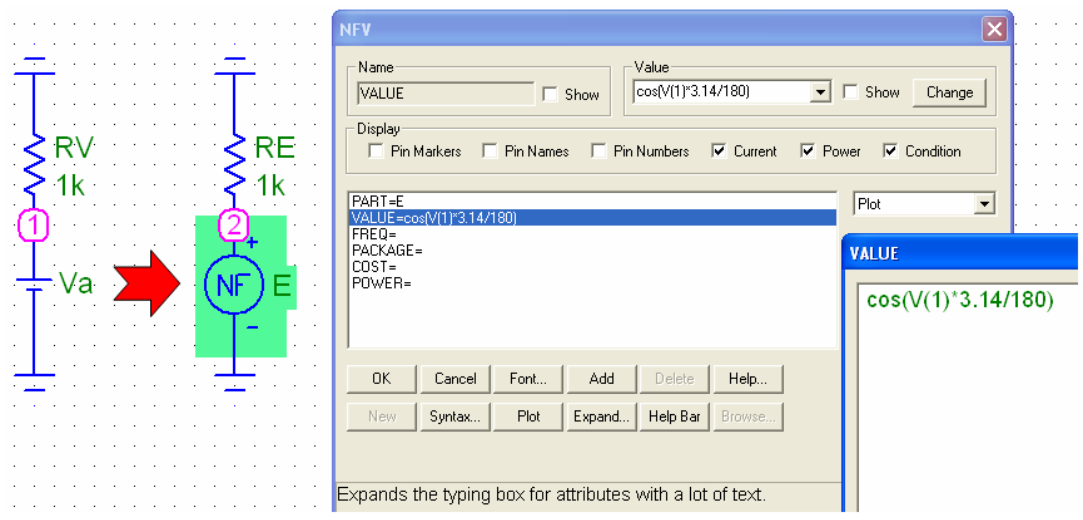

Fig. 3. An example of an NFV-type voltage source control circuit

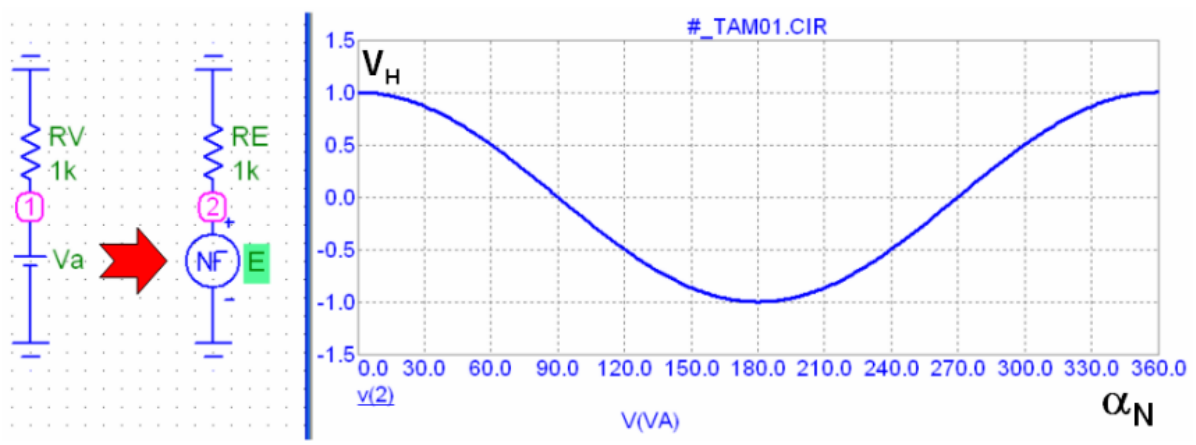

Fig. 4. An example of the modelling analogy between Hall voltage $V_{H}$ and angle $\alpha_{N}$
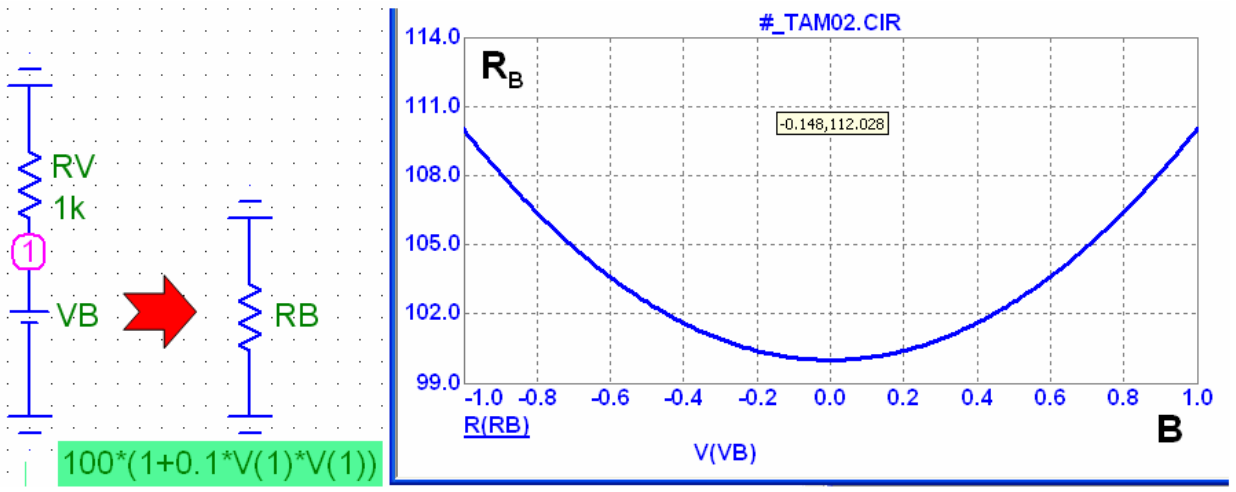

Fig. 5. A sample specification for a magnetoresistive structure model. 


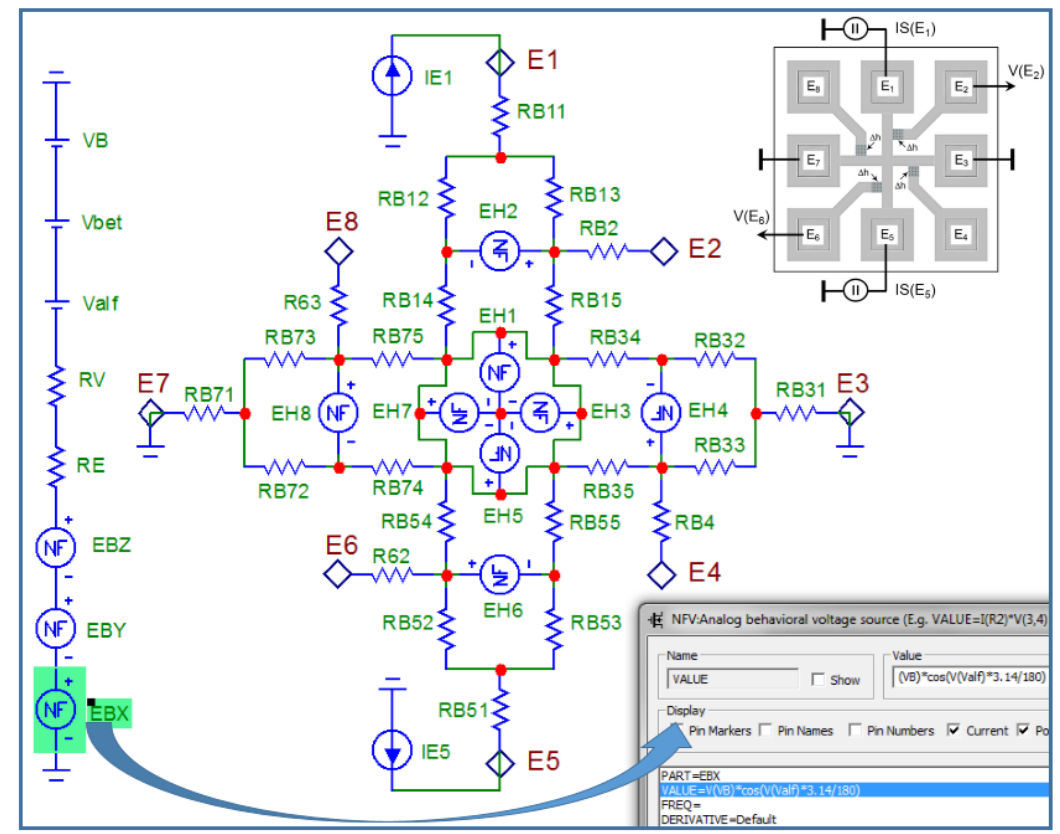

Fig. 6. The SPICE model equivalent circuit.
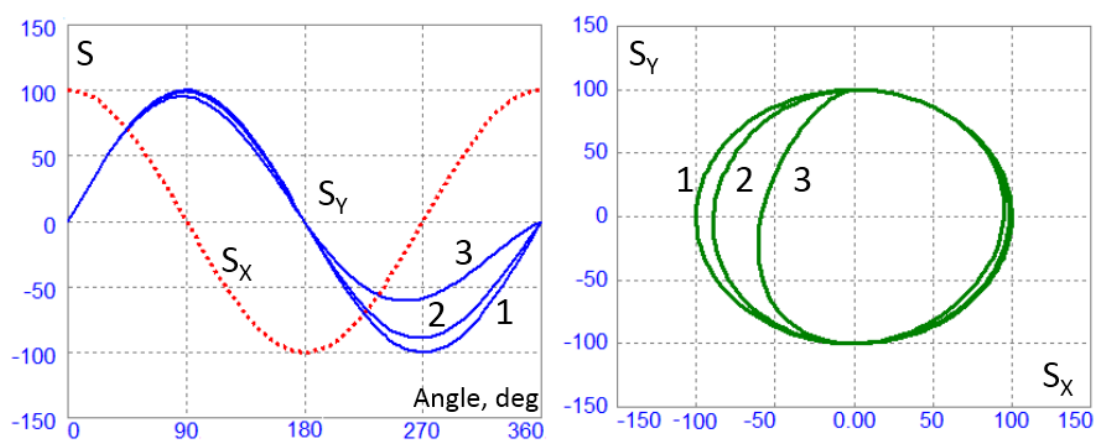

Fig. 7. Sample simulation results.

These functional components can be placed and connected arbitrarily since it's their numerical values and not the result of interaction in the circuit serve as the informative value in this representation. However, one should make sure that there are no idle speed modes or short circuits in the voltage sources since they usually cause a SPICE syntax error. When appropriate, other functional components may be added to the model including those needed for description of the planar effect coefficients and SHS asymmetry.

Then upon the obtained numerical values of the functional components, the equivalent circuit of the SHS structure is synthesized. For this purpose, we use the above-mentioned controlled resistive components $\mathrm{RB}^{* *}$ and voltage sources $\mathrm{EH}^{* *}$ (here $* *$ denote the component number). At the final stage, we equip the synthesized equivalent circuit with an electric feeding circuit including current sources IE1, IE5.

Fig. 7 (to the left) shows sample simulation results including the normalized signals $S_{X}$ and $S_{Y}$ that represent the dependencies of the output voltage differences between electrodes E2 and E6 (signal $\mathrm{S}_{\mathrm{X}}$ ) and electrodes $\mathrm{E} 4$ and E8 (signal $\mathrm{S}_{\mathrm{Y}}$ ) on the rotation angle (Angle, deg) of the structure in the magnetic field. The simulation was conducted for three values $(1,2,3)$ of the structure asymmetry that was marked with some discrepancies in the modulation coefficients of the model components' parameters. Fig. 7 (to the right) visualizes an evaluation of such asymmetry with normalized dependencies $S_{Y}=f_{X Y}\left(S_{X}\right)$. When the structure is ideally symmetric, the following condition should hold: $S_{X}^{2}+S_{Y}^{2}=$ const . Taking into account this fact, one can assess the asymmetry by the extent to which function $f_{X Y}$ deflects $(2,3)$ from an ideal circle $(1)$.

The parameters of the presented SHS model can be corrected according to the experimental results. The simulation results are useful for development and optimization of SHS calibration techniques.

\section{Approbation}

Prototypes of the presented 3-D magnetic sensors were manufactured by traditional thin-film technology on semi-insulating GaAs plates. The thickness of the active InSb layer is $10^{-5} \mathrm{~m}$, whereas its doping concentration is $\mathrm{N}=10^{16} \mathrm{~cm}^{-3}$. The sensor structure was implemented by 

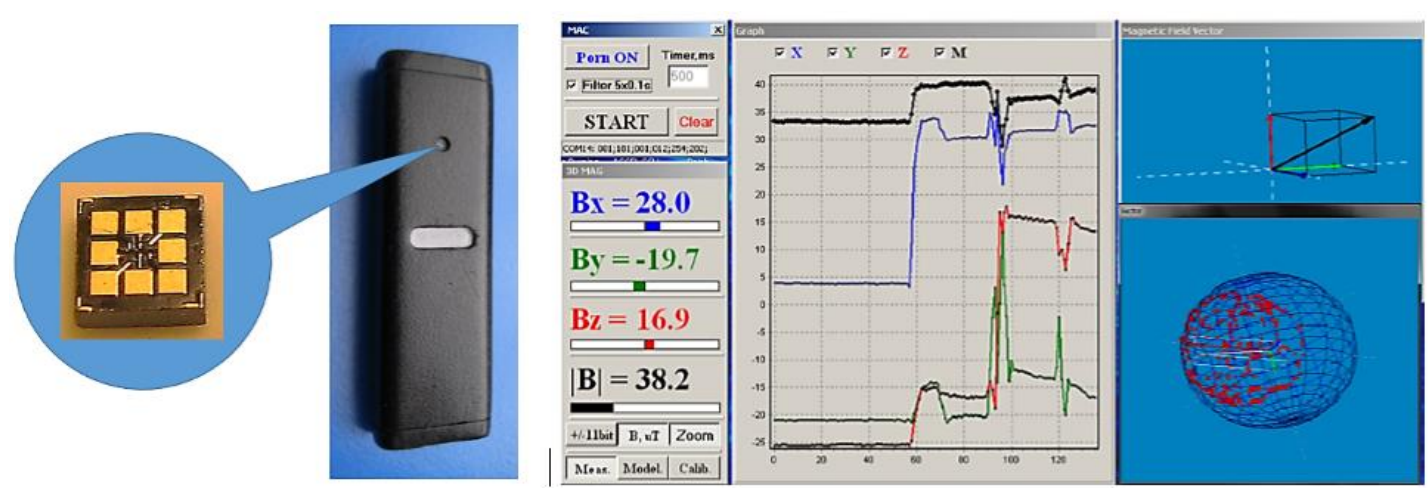

Fig. 8. Prototype of the hardware-software complex for measuring the magnetic flux density vector.

selective etching of the active layer according to the above-mentioned design and its contact areas were obtained by metallization with Au. The size of the chips is $1 \mathrm{~mm} \times 1 \mathrm{~mm}$. The prototypes have sensitivity of approximately $0.3 \mathrm{~V} /(\mathrm{A} \cdot \mathrm{T})$ for axes $\mathrm{B}_{\mathrm{X}}$ and $\mathrm{B}_{\mathrm{Y}}$ and $2 \mathrm{~V} /(\mathrm{A} \cdot \mathrm{T})$ for axis $\mathrm{B}_{\mathrm{Z}}$. Their cross-sensitivity does not exceed $10 \%$.

The 3-D sensors were verified using hardwaresoftware complex for magnetic field measurement whose prototype is depicted in Fig. 8. The embedded system of the 3-D sensor is based upon the microprocessor noiseimmune signal transducer for galvanomagnetic smart sensor devices [29] implemented using the programmable system-on-chip PSoC of 5LP Family by Cypress Semiconductor Corporation [30].

\section{Conclusions}

The work presents a new design of a 3-D magnetic sensor based on SHS. Combining current flows in it, one measures voltages upon which one then calculates projections $\mathrm{B}_{\mathrm{X}}, \mathrm{B}_{\mathrm{Y}}, \mathrm{B}_{\mathrm{Z}}$ of the magnetic flux density vector. The proposed 3-D sensor includes one traditional Hall sensor whose sensitivity axis $(Z)$ is perpendicular to the semiconductor layer plane and two vertical SHSs whose sensitivity axes, $\mathrm{X}$ and $\mathrm{Y}$ correspondingly, are parallel to this plane. In contrast to known solutions, the potential (Hall) electrodes of the vertical SHSs are formed in the intermediate area between the semiconductor layer and the dielectric substrate and not on the surface of the semiconductor layer. Due to this solution, such sensors can be manufactured by traditional thin-film technology.

A SPICE model of the 3-D magnetic sensor based on SHS has been developed. The model incorporates controlled voltage sources for simulation of Hall voltages and controlled resistive components for modelling the magnetoresistive modulation of the structure ohmic areas. The functional relationships between the parameters of the Hall sensors and the magnetic flux density vector projections are implemented by formal analogues and described by trigonometric functional dependencies including those existing between the Hall and ohmic signal components and the sensor tilt angle in the magnetic field.

The prototypes of the 3-D magnetic sensors presented in this work were manufactured using InSb structures upon semi-insulating GaAs plates. The size of the chips is $1 \mathrm{~mm} \times 1 \mathrm{~mm}$. The prototypes have sensitivity of approximately $0.3 \mathrm{~V} /(\mathrm{A} \cdot \mathrm{T})$ for axes $\mathrm{B}_{\mathrm{X}}$ and $\mathrm{B}_{\mathrm{Y}}$ and $2 \mathrm{~V} /(\mathrm{A} \cdot \mathrm{T})$ for axis $\mathrm{B}_{\mathrm{Z}}$. The $3-\mathrm{D}$ sensors were verified using hardware-software complex for measurement of the magnetic flux density vector built upon PSoc of 5LP Family by Cypress Semiconductor Corporation.

Barylo G.I. - professor, Dr.Sc. Tech., associated professor of electronic devices department;

Holyaka R.L. - professor, Dr.Sc. Tech., professor of electronics and information technology department;

Marusenkova T.A. - PhD Tech., associated professor, associated professor of software department;

lvakh M.S. - PhD Tech., senior lecturer of electronic devices department.

[1] N. Hadjigeorgiou, K. Asimakopoulos, K. Papafotis, P.P. Sotiriadis, Sensors Journal (2020); https://doi.org/10.1109/JSEN.2020.3045660.

[2] E. Quandt, S. Stein, M. Wuttig, International Magnetics Conference (INTERMAG) (IEEE, Nagoya, 2005). P. 967; https://doi.org/10.1109/INTMAG.2005.1463912.

[3] X. Zhao, Y. Bai, Q. Deng, C. Ai, X. Yang, D. Wen, Sensors Journal 17(18), 5849 (2017); https://doi.org/10.1109/JSEN.2017.2736639.

[4] H. Pan, L. Yao, S. He, W. Li, L. Li, J. Sha, Third International Conference on Instrumentation, Measurement, Computer, Communication and Control (IEEE, Shenyang, 2013), P. 252; https://doi.org/10.1109/IMCCC.2013.60.

[5] S.V. Lozanova, A.J. Ivanov, C.S. Roumenin, XXVIII International Scientific Conference Electronics (IEEE, Sozopol, 2019). P. 1; https://doi.org/10.1109/ET.2019.8878505. 
[6] C. Leepattarapongpan, T. Phetchakul, N. Penpondee, P. Pengpad, A. Srihapat, E. Chaowicharat, C. Hruanun, A. Poyai, Sensors (IEEE, Limerick, 2011); https://doi.org/10.1109/ICSENS.2011.6127079.

[7] P. Beran, M. Klöhn, H. Hohe, Magnetics Letters 10, 1 (2019); https://doi.org/10.1109/LMAG.2019.2944581.

[8] V.S. Luong, S. Yu-Hsin, L. Chih-Cheng, J. Jen-Tzong, H. Jen-Hwa, L. Ming-Han, W. Jong-Ching, L. MengHuang, C. Ching-Ray, Transactions on Nanotechnology $17(1), \quad 11 \quad$ (2018); https://doi.org/10.1109/TNANO.2017.2660062.

[9] C. Guo, H. Zhang, H. Guo, L. Chen, W. Chen, N. Yu, Sensors Journal 21(3), 3121 (2021); https://doi.org/10.1109/JSEN.2020.3028149.

[10] P. Beran, M. Stahl-Offergeld, V. Peters, D. Krause, H. Hohe, Transactions on Magnetics 55(1), 1 (2019); https://doi.org/10.1109/TMAG.2018.2873238.

[11] O. Boyko, R. Holyaka, Z. Hotra, 14th International Conference on Advanced Trends in Radioelecrtronics, Telecommunications and Computer Engineering (TCSET) (IEEE, Slavske, 2018). P. 697; https://doi.org/10.1109/TCSET.2018.8336296.

[12] A. Dwivedi, A. Ramakrishnan, A. Reddy, K. Patel, S. Ozel, C. D. Onal, Sensors Journal 18(9), 3852 (2018); https://doi.org/10.1109/JSEN.2018.2814839.

[13] D. Ettelt, P. Rey, G. Jourdan, A. Walther, P. Robert, J. Delamare, Journal of Microelectromechanical Systems 23(2), 324 (2014); https://doi.org/10.1109/JMEMS.2013.2273362.

[14] M. Ortner, C. Huber, N. Vollert, J. Pilz, D. Süss, SENSORS (IEEE, Glasgow, 2017). P. 1 https://doi.org/10.1109/ICSENS.2017.8233930.

[15] D. Fedasyuk, R. Holyaka, T. Marusenkova, 15th International Conference on Advanced Trends in Radioelectronics, Telecommunications and Computer Engineering (TCSET), (IEEE, Lviv-Slavske, 2020). P. 46; https://doi.org/10.1109/TCSET49122.2020.235387.

[16] R. Holyaka, I. Prudyus, G. Barylo, T. Marusenkova, S. Fabirovskyy, International Conference on Information and Telecommunication Technologies and Radio Electronics (UkrMiCo) (IEEE, Odessa, 2019). P. 1 https://doi.org/10.1109/UkrMiCo47782.2019.9165386.

[17] I. Kogut, A. Druzhinin, V. Holota, Advanced Materials Research 276, 137 (2011); https://doi.org/10.4028/www.scientific.net/amr.276.137.

[18] I. Kogut, V. Holota, A. Druzhinin, V. Dovhij, Journal of Nano Research 39, 228 (2016); https://doi.org/10.4028/www.scientific.net/JNanoR.39.228.

[19] S. Nazari Nejad, R. Mansour, Transactions on Magnetics $52(1), \quad 1 \quad$ (2016); https://doi.org/10.1109/TMAG.2015.2476489.

[20] P. Meier, K. Rohrmann, M. Sandner, M. Prochaska, 62nd International Midwest Symposium on Circuits and Systems (MWSCAS) (IEEE, Dallas, 2019). P. 1005; https://doi.org/10.1109/MWSCAS.2019.8885265.

[21] Z. Hotra, R. Holyaka, I. Bolshakova, I. Yurchak, T. Marusenkova, Perspective Technologies and Methods in MEMS Design (IEEE, Polyana, 2011). P. 5.

[22] Z. Hotra, R. Holyaka, I. Bolshakova, I. Yurchak, T. Marusenkova, 11th International Conference The Experience of Designing and Application of CAD Systems in Microelectronics (CADSM) (IEEE, Polyana, 2011). P. 413.

[23] R. Berdan, C. Lim, A. Khiat, C. Papavassiliou, T. Prodromakis, IEEE Electron Device Letter 35, 1 (2014); https://doi.org/10.1109/LED.2013.2291158.

[24] A. Aziz, S. Ghosh, S. Datta, S.K. Gupta, Electron Device Letters 37(6), 805 (2016); https://doi.org/10.1109/LED.2016.2558149.

[25] Y. Moumouni, R. Jacob Baker, 58th International Midwest Symposium on Circuits and Systems (MWSCAS) (IEEE, Fort Collins, 2015). P. 1; https://doi.org/10.1109/MWSCAS.2015.7282015.

[26] M. Crescentini, A. Romani, E. Sangiorgi, 15th International Conference on Ultimate Integration on Silicon (ULIS) (IEEE, Stockholm, 2014). P. 89; https://doi.org/10.1109/ULIS.2014.6813923.

[27] A. Rossini, F. Borghetti, P. Malcovati, F. Maloberti, 12th International Conference on Electronics, Circuits and Systems (IEEE, Gammarth, 2005). P. 1; https://doi.org/10.1109/ICECS.2005.4633482.

[28] G. Sung, W. Wang, C. Yu, Sensors Journal 17(21), 6880 (2017); https://doi.org/10.1109/JSEN.2017.2754295.

[29] R. Holyaka, I. Yurchak, T. Marusenkova, V. Ilkanych, International Conference on Modern Problem of Radio Engineering, Telecommunications and Computer Science (IEEE, Lviv, 2012). P. 430.

[30] H. Barylo, O. Boyko, I. Helzhynskyy, R. Holyaka, T. Marusenkova, M. Ivakh, 16th International Conference on the Experience of Designing and Application of CAD Systems (CADSM) (IEEE, Lviv, 2021). P. 58; https://doi.org/10.1109/CADSM52681.2021.9385254. 
Г.І. Барило, Р.Л. Голяка, Т.А. Марусенкова, М.С. Івах

\title{
Структура та 3-D модель твердотільного тонкоплівкового сенсора магнітного поля
}

\author{
Національний університет «Львівська політехніка», м. Львів, Україна, roman.l.holiaka@lpnи.иа
}

Векторні 3-D сенсори магнітного поля становлять основу вимірювальних пристроїв для картографування магнітного поля та магнітного трекінгу. Здебільшого, в таких 3-D сенсорах використовують спеціальні конструкції на основі розщеплених холлівських структур (РХC). Конструкція 3-D сенсора магнітного поля на основі PXC - це об'ємна напівпровідникова інтегральна структура 3 8-ма i більше виводами, комбінуючи проходження струму через які та вимірюючи відповідні напруги, визначають складові поля $\mathrm{B}_{\mathrm{X}}, \mathrm{B}_{\mathrm{Y}}, \mathrm{B}$. В даній роботі представлено нова структурна реалізація 3-D твердотільних сенсорів магнітного поля, яка не потребує ізоляції p-n переходами та може бути реалізованою на тонкоплівковій меза-технології традиційних холівських перетворювачів, зокрема на основі плівок антимоніду індію (InSb). Крім того, в роботі представлена SPICE модель 3-D сенсора магнітного поля, 3 використанням якої вирішується задача розробки та оптимізації методики калібрування запропонованого сенсора.

Ключові слова: 3-D сенсор магнітного поля, розщеплена холлівська структура, SPICE модель. 